\title{
Hungarian law will protect academics strapped for cash
}

Budapest. The rights of researchers, students and teachers in universities and research institutes to work with total political and ideological freedom will be written into Hungary's new constitution this autumn.

The new laws will formalize the quiet research revolution that has been going on for the past few years (see Nature 352, 745; 1991). They provide a silver lining to continuing clouds of economic misfortune and follow several years of steady progress towards westernization of research organization after the fall of Hungary's 40-year-old communist regime.

The reforms, outlined in the "Act of the Academy', restore the autonomy of the Hungarian Academy of Sciences, as well as restructuring its 39 institutes. They are based on the efforts of Domokos Kosáry, who spent four years in jail as a communist dissident and who was elected president of the academy in 1990 . The academy, founded in 1825, runs most of Hungary's independent research institutes as well as looking after the interests of national science.

Many of the reforms are already under way. More than 200 scientists, half from universities, are analysing the recent performance of the academy's institutes as members of 40 evaluation committees. This month, teams from the International Council of Scientific Unions (ICSU) will assess three of the larger institutes. Their findings will be used to determine how next year's budget is allocated.

Resources are now allocated by the Hungarian Research Fund, known as OTKA, under a peer-review system established in 1986. OTKA is rethinking its original deci-

sion to distribute its relatively small fund fairly evenly between successful applicants and is preparing to give proportionately higher rewards for excellence.

The Higher Education Act - the first comprehensive legislation in Hungary's 600 year history of higher education - is also expected to be passed this autumn. It provides autonomy for universities and reestablishes their rights, removed during the communist years, to conduct postgraduate research, award PhDs and carry out the process of 'habilitation' (tenure). Until now, two parallel systems of research-based doctorates have existed: the two-year 'university doctor', awarded by the universities, and the 'candidate of science', awarded by a now-defunct government committee often accused of abusing its political power. In their place will be a single $\mathrm{PhD}$ programme similar to those in the West.

These new postgraduate activities will be monitored by an accreditation committee made up of Hungarian and foreign academic researchers and experts from outside higher education. One of the committee's first tasks will be to assess the country's 30 universities in the same way that the research institutes were judged.

But rising political fortunes must contend with a failing economy. This year's research budget, frozen at HUF4.7 billion (US\$60 million), is being devoured by an inflation rate of 30 per cent. According to István Láng, general secretary of the Hungarian academy, research has done better than other government programmes but inadequate funding makes it essential to pick the best research.

Alison Abbott

\section{Hard times for high- $T_{c}$ press}

Nikkei Superconductors, a twice-monthly Japanese newsletter created during the 1987 boom in high-temperature superconductors, will cease publication later this month. It joins at least four other superconductivity publications that have folded or cut back recently, victims of a slowing of the rate of scientific progress in the field.

In the United States, Supercurrents has closed and Superconductivity News, after a string of financial problems, has missed several issues. Its editors are considering reconfiguring the newsletter as a one- or two-page weekly. For the moment, that leaves just High $T$ Update, a governmentsubsidized newsletter, and the commercial publications Superconductor Week and the quarterly Superconductor Industry. Two international superconductivity newsletters published in Britain by Elsevier are still in operation, although the company says that circulation is down by about 20 per cent. And two journals funded by the British government-Superconductivity Titles and Superconductor Focus - were terminated last December as part of an overall belttightening.

Kevin Ott, director of the Washingtonbased Council on Superconductivity for American Competitiveness, attributes the decline in publications to an evolution in the field towards commercialization. Although progress in basic research has slowed, interest in the application of superconductors is increasing. Attendance at last month's biennial Applied Superconductivity Conference in Chicago was 25 per cent higher than in 1990 , at a record 1,500. From our bureaus
NEWS IN BRIEF

Munich. The heaviest known chemical elements - with half-lives of around $5 \mathrm{~ms}$. - were finally named last week by scientists at the Institute of Heavy Ion Research in Darmstadt, Germany, where they were created by fusion reactions in the early 1980 s. Element 107 is to be called nielsbohrium, after the atomic physicist Niels Bohr. Element 108, a

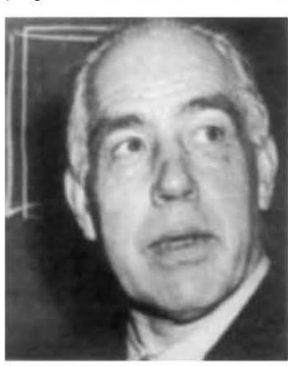

fusion product of $\mathrm{Pb} 208$ and Fe58, is now hassium, named for the German state of Hessen, which supports the institute financially. Element 109 meitnerium is a tribute to Niels Bohr Lise Meitner, whose theoreti-

cal interpretation of Otto Hahn's experiments was fundamental to the discovery of nuclear fission.

Unlike some previous attempts to name transuranic elements, this terminology is expected to be accepted by the international scientific community. During the cold war, element 104 was discovered concurrently in the Soviet Union and the United States, but debate continues on whether its name should be kurchatovium or rutherfordium, after the leading English and Soviet nuclear physicists of their time.

A.A.

Washington. Seventy-one days after he received the first baboon-to-human liver transplant, a 35-year-old man died last week at the University of Pittsburgh. After his death of a haemorrhage in the brain, the university disclosed that the patient had been HIV-positive, although he had not yet begun to exhibit AIDS-defining symptoms. University officials said that the condition did not appear to have contributed to his death.

The patient, whose identity has been withheld, was considered to be a poor candidate for a human liver because his own liver had been destroyed by hepatitis $B$, which would have presumably attacked any human transplant. Rather than depleting a supply of human organs that is already too small to meet demand, the surgeons decided to use the liver of a baboon, which is thought to be immune to hepatitis $B$. The Pittsburgh surgeons said that an autopsy revealed only mild evidence of rejection, adding that they will continue with plans to transplant three more baboon livers into humans.

C.A.

Beijing. The National Natural Science Foundation of China, created in 1986 , has received an increase of 28 per cent in its budget for 1992 . The foundation has yet to decide whether to use the extra money to increase the size of the average grant or to make additional awards. Y.Q.L. 